\title{
The Role of Early Maladaptive Schemas on Coping Styles and Fear of Recurrence in Women With Breast Cancer: A Cross-Sectional Study
}

\author{
Faezeh Arabameri ${ }^{1}$, Anahita Khodabakhshi-Koolaee ${ }^{1, *}$ \\ ${ }^{1}$ Department of Psychology and Education Sciences, Faculty of Humanities, \\ Khatam University, Tehran, Iran \\ *Corresponding author: Anahita Khodabakhshi-Koolaee, Department of \\ Psychology and Educational Sciences, Faculty of Humanities, Khatam Uni- \\ versity, Tehran, Iran. Tel: +982189174119; Fax: +982189174500; E-mail: \\ a.khodabakhshid@khatam.ac.ir
}

DOI: $10.30699 /$ mci.5.4.578-1

Submitted: 18 September 2021

Revised: 4 October 2021

Accepted: 10 December 2021

e-Published: 28 December 2021

\section{Keywords:}

Recurrence

Schema Therapy

Adaptation, Psychological

Neoplasms
Introduction: Maladaptive schemas influence the mental and physical health of patients. This study aimed to examine the role of early maladaptive schemas on coping styles and fear of recurrence in women with breast cancer (BC).

Methods: This study was conducted; using a descriptive-correlational design. The research population included all female patients with $\mathrm{BC}$ who were referred to the radiotherapy ward of Five Hospitals in the center of Tehran from June to December 2020. The participants were 118 BC patients who were selected; using a simple random sampling technique. The inclusion criteria were undergoing radiotherapy, having $\mathrm{BC}$ surgery at least one month ago, and having at least a middle school education to answer questions independently. The exclusion criteria were being a widow and/or suffering from other specific physical and mental health problems in addition to cancer. The participants completed the Schema Questionnaire - Short Form (SQ-SF) (Young, 1998), the Coping Inventory for Stressful Situations (CISS; Endler \& Parker, 1990), and Fear of Cancer Recurrence Inventory (FCRI). The collected data were analyzed; using the Pearson correlation coefficient and multiple linear regression analysis.

Results: Data analysis demonstrated that emotional inhibition, entitlement/grandiosity, enmeshment/undeveloped self, unrelenting standards/hyper criticalness, and insufficient self-control/self-discipline were positively correlated with fear of cancer recurrence (FCR). The strongest correlations with fear of recurrence were related to the emotional inhibition $(\mathrm{r}=0.35)$, unrelenting standards/hyper criticalness, and entitlement/grandiosity $(\mathrm{r}=0.28)(\mathrm{P}<0.001)$. Emotional and avoidance coping styles were also associated with the fear of recurrence $(r=0.50$ and $r=0.20)$. Furthermore, the independent variables could explain $41 \%$ of the variances in FCR $(\mathrm{P}<0,001)$.

Conclusions: Understanding the role of dysfunctional cognitive schemas on coping mechanisms and FCR can help clinicians and mental health professionals to form treatment interventions for BC patients.

(C) 2021. Multidisciplinary Cancer Investigation

\section{INTRODUCTION}

Breast cancer $(\mathrm{BC})$ is the most common cancer in women worldwide and the second most common cancer among all cancers. Nevertheless, approximately $24.5 \%$ of all cancer deaths and $15.5 \%$ of total deaths are related to $\mathrm{BC}[1,2]$. According to the latest statistics, 13120 Iranian women have been diagnosed with $\mathrm{BC}$ in 2015 [3]. However, the advances in cancer diagnostic and therapeutic 
methods have increased the survival rate. Thus, more attention has been paid to the psychological consequences followed by cancer diagnosis and treatment. One of the most common psychological problems that many cancer patients experience during active treatment or survival is fear of cancer recurrence (FCR) that is defined as the fear that cancer could return or progress in the same place or another part of the body $[4,5]$. It is estimated that $73 \%$ of cancer survivors experience FCR [6] and 55\%-90\% of $\mathrm{BC}$ patients report FCR during the survival period [7]. A high level of FCR reduces patients' quality of life and leads to dysfunctional behaviors such as avoidant behaviors, sensitivity, and sensitivity/ alertness to physical symptoms, uncertainty, and inability to plan for the future [7]. It has been shown that women, young people, individuals with lower education, and those having at least one child are more likely to experience higher levels of FCR [6]. Research has shown that FCR persists for years after treatment. One study found that the level of FCR can be predicted approximately 2 months after the end of treatment based on its initial level at the beginning of radiation therapy, and the course of the disease during radiation therapy [7]. Fardell et al., suggested several key maintaining processes of FCR; resulting in a theoretical model with dysfunctional cognitive processes at its core [8]. To date, 6 theoretical models have been proposed to explain the causes of FCR. A common feature of all these theories is their focus on the cognitive content and cognitive processing underlying the FCR. However, these models can be distinguished by their particular focus on metacognitive beliefs about anxiety, uncertainty, cognitive bias toward physical symptoms, or social context [9]. According to the Cancer Anxiety Model [10], pre-existing schemas, past experiences with cancer, ambiguity intolerance, and metacognitive beliefs about interacting with the inherent nature of cancer cause severe anxiety. Anxiety activates cognitive processes characterized by alertness, worry, and rumination. Trying to cope by re-establishing control and a pattern of alertness to cancer-related symptoms or avoidance in the context of a variety of underlying factors can exacerbate the anxiety.

Accordingly, it can be suggested that the FCR and how to deal with it depends on people's perceptions of the possibility of recurrence [11]. Schema therapy is one of the constructs that are very useful in understanding how people respond to cancer diagnosis and treatment [12]. Schema therapy focuses on the concept of "early maladaptive schemas" [13]. Schemas are cognitive constructs that include fixed beliefs and patterns that have been formed from childhood. Using these beliefs, a person understands his/her surrounding world and acts in his/her confirmed schemas. These schemas are consistent in the course of life and are resistant to change. Early schemas are useful guides because they are compatible with the child's environment. However, they have limited usage during adulthood and in the changed environment of individuals; causing misinterpretation and possibly leading to anxiety, depression, and other psychological harms [14]. Young identified 18 early maladaptive schemas organized in five domains which correspond to the five basic psychological needs: 1) Disconnection and rejection (abandonment/instability, mistrust/abuse, emotional deprivation, defectiveness/shame, and social isolation/ alienation); 2) Impaired autonomy and performance (dependence/incompetence, vulnerability to harm or illness, enmeshment/undeveloped self, and failure to achieve); 3) Impaired limits (entitlement/grandiosity and insufficient self-control/self-discipline); 4) Otherdirectedness (subjugation, self-sacrifice, and approvalseeking/recognition-seeking); and 5) Overvigilance and inhibition (negativity/pessimism, emotional inhibition, unrelenting standards/hyper criticalness, and punitiveness) [15].

Another common aspect of FCR descriptive theories is the consideration of behavioral and coping responses [9]. Coping refers to a set of behavioral and cognitive actions and processes that people use to manage and reduce stress when faced with stressful situations. What is important in facing stressful situations is how the person assesses stress and ways to cope with it $[16,17]$. People deal with fear in different ways; depending on their personality, environmental conditions, and culture. The role of culture is very important because of its impact on how people think and react to stress. Different cultural beliefs about the cause of illness lead to the adoption of different coping strategies $[18,19]$. There are three main strategies used for coping with stress: problem-focus, emotion-focus, and avoidance [20]. Studies have shown different and sometimes conflicting results on the relationship between FCR and coping strategies. These differences could be 
attributed to different measurement methods and the small number of studies in this field [4]. A qualitative systematic review and meta-synthesis of patients' experiences of FCR revealed two prominent and contradictory tendencies concerning FCR: avoidance and confrontation [6]. Early maladaptive schemas as deep cognitive constructs can be activated in cancer diagnosis settings and affect patients' perceptions and interpretations. Although theories on the FCR point to the role of schemas and the patient's previous beliefs, no study has yet addressed the relationship between early maladaptive schemas and FCR. Identifying the role of coping strategies in FCR is also essential for developing training interventions. However, few researchers have quantitatively examined this relationship. The current study aims to explore the role of early maladaptive schemas on coping styles and FCR in women with BC.

\section{METHODS}

Study setting and population: The participants in this study were patients with $\mathrm{BC}$ who were referred to the radiotherapy wards of five hospitals (Firoozgar Hospital, Roshana Cancer Center, Pars Hospital, Salamat Farda Hospital, and Asia Hospital) in the center of Tehran. The questionnaires were completed by the patients; while waiting for a radiation therapy session. The data were collected by the researcher from June to December 2020. Study design, sample size, and sampling: This study was conducted; using a descriptive-correlational design. A simple random sampling technique was then used to select study subjects from the registration list; using the lottery method. The enrolment in the study was voluntary. The inclusion criteria were as follows: 1) undergoing radiotherapy; 2) having BC surgery for at least one month ago; and 3) having at least middle school education to answer questions independently. The exclusion criteria were being a widow and/or suffering from other specific physical and mental health problems in addition to cancer. These cases were assessed; using a demographic questionnaire. Finally, 118 patients met the inclusion criteria and completed the data.

\section{Data Collection}

\section{Demographic information}

A prepared patient information form was used by the researchers. The form contained 7 questions that assessed the patients' age, marital status, educational status, and employment status, number of children, the date of BC surgery, and the presence of chronic illness.

\section{Fear of cancer recurrence inventory}

FCR was assessed; using the Fear of Cancer Recurrence Inventory (FCRI). This scale was constructed by Simard and Savard in 2009. The English version of FCRI has 42 items. FCRI is a multidimensional inventory being used for all cancer patients. The questionnaire was originally validated in French-speaking patients with different cancers, and the English version was developed later by the same authors. The inventory assesses seven aspects associated with FCR including triggers, severity, psychological distress, functioning impairments, insight, reassurance, and coping strategies. The scores of each subscale were added together to reach of an overall score. Scores range from 0-168 and higher scores indicate greater FCR. The original French version was reported to have high internal consistency (0.95) and temporal stability (0.89). Bateni et al., calculated the internal consistency of the Persian version of FCRI to be as follows: $\alpha=0.86$ [21].

\section{Early maladaptive schemas questionnaire}

The Young Schema Questionnaire-Short Form (YSQ-SF) is a 75-item scale [22]. The items measure the presence of 15 maladaptive schemas. Answers are scored on a 6-point Likert scale; ranging from 1 (totally disagree) to 6 (totally agree). The average score of each schema was calculated by summing the outcomes of all related items and then dividing the result by the total number of questions. Good internal consistency, reliability, and validity of this version have been previously demonstrated [23]. The reliability and validity of the Persian version of this instrument were also previously assessed according to Cronbach's alpha, its internal consistency was reported to be 0.97 in the female group and 0.98 in the male group [24].

\section{Coping styles inventory}

Coping Inventory for Stressful Situations (CISS): This scale was made by Endler and Parker in 1990. The CISS is a self-report scale that including of 48 items to assess the emotion, task, and avoidance- 
oriented coping styles. Subjects respond to this scale on a five-point Likert scale; ranging from 1 (not at all) to 5 (very much) [25]. The CISS is made up of three sub-scales: task-oriented coping, emotionoriented coping, and avoidance-oriented coping. Adequate psychometric properties of English and Persian versions of the scale have been previously reported [26].

\section{Data Analysis}

SPSS 25 software was used for data analysis. Besides, statistical measures including mean and standard deviation were used to describe the main variables. The normality of the variables was assessed; using skewness and kurtosis indices and the KolmogorovSmirnov test. Pearson correlation test and multiple linear regression analysis were also used to test the research hypotheses. The maximum alpha error for testing the hypotheses was set at 0.05 .

The ethical considerations in this research project were approved by the Khatam University with (Code: IR.KHATAM.REC.1399.3). The participants of the study were explained to the patients and verbal consent was received from them. The patients were also assured that their personal information would only be used for scientific purposes.

\section{RESULTS}

Table 1 shows the descriptive statistics for the participants' demographic data. The participants' mean age was 49.25 years $(\mathrm{SD}=13.22)$. Table 2 presents the mean and standard deviation indices for 15 early maladaptive schemas, 3 coping strategies, and the FCR. Table 3 shows the relationships between early maladaptive schemas and coping strategies. The findings confirmed that the FCR was correlated with the five schemas of enmeshment, emotional inhibition, unrelenting standards, entitlement, and self-control $(\mathrm{P}<0.001)$. An analysis of the intensity of correlations suggested that emotional inhibition $(\mathrm{r}=0.35)$, unrelenting standards, and entitlement $(r=0.28)$ had respectively the strongest correlations with the FCR.

The findings also showed that emotion-oriented coping strategies and avoidance strategies had positive significant correlations with $\mathrm{FCR}$ at a confidence level of at least $95 \%(\mathrm{P}<0.05)$; indicating that increased emotion-focused coping and avoidance strategies are associated with increased
FCR. Besides, no relationship was observed between problem-oriented coping strategy and FCR $(\mathrm{P}<0.05)$. Stepwise regression analysis was performed to investigate the effect of early maladaptive schemas and initial strategies as the independent or predictive variables on the FCR as the dependent variable. The results of this analysis and the significant variables that remained in the model are presented in Table 4.

Table 1: The Participants' Demographic Characteristics $(\mathrm{N}=118)$

\begin{tabular}{lcc}
\hline & Frequency, No. & Percent \\
\hline Age Groups, $\mathbf{y}$ & & \\
$\mathbf{3 0 - 4 0}$ & 36 & 30.50 \\
\hline $\mathbf{4 1 - 5 0}$ & 39 & 33.05 \\
$\mathbf{5 1 - 6 0}$ & 20 & 16.94 \\
$\mathbf{\mathbf { 6 0 0 }}$ & 23 & 19.49 \\
\hline Marital Status & & \\
\hline Married & 109 & 92.37 \\
\hline Single & 9 & 7.62 \\
\hline Educational Level & & \\
\hline Less than high school graduate & 23 & 19.49 \\
\hline High school graduate & 49 & 41.52 \\
\hline University & 46 & 38.98 \\
\hline Employment Status & & \\
Yes & 39 & 33.05 \\
\hline No & 79 & 66.94 \\
\hline Children & & \\
\hline Yes & 102 & 86.44 \\
\hline No & 16 & 13.55 \\
\hline Time Since Surgery, mo & & \\
\hline 1-2 & 26 & 22.03 \\
\hline 3-4 & 40 & 33.89 \\
\hline 4-5 & 21 & 17.79 \\
\hline $\mathbf{6}$ & 31 & 26.27 \\
\hline
\end{tabular}

The value of the F-test was 15.37 which was at the significance level of less than $0.05(\mathrm{P}<0.05)$. The Durbin-Watson test was used to evaluate the independence of the residuals (no serial correlation between the residuals or errors). The F-value in the present study was 1.70 . The independent variables in the model could explain about $41 \%$ of the variances in the FCR. The results suggest that of the 15 early maladaptive schemas and 3 coping strategies, emotion-oriented coping style, enmeshment/ underdeveloped self, emotional inhibition, inadequate self-control, and unrelenting standards had a significant effect on the FCR $(\mathrm{P}<0.05)$.

\section{DISCUSSION}

This study examined the relationship between early 
Table 2: Means and Standard Deviations (SD) of 15 EMS, Coping Styles, and Fear of Cancer Recurrence (FCR)

\begin{tabular}{lcc}
\hline & Mean & SD \\
\hline Abandonment/Instability & 15.33 & 6.27 \\
\hline Emotional Deprivation & 12.67 & 5.42 \\
\hline Mistrust/Abuse & 12.83 & 5.18 \\
\hline Social Isolation/Alienation & 11.90 & 5.43 \\
\hline Defectiveness/Shame & 11.81 & 5.48 \\
\hline Dependence/Incompetence & 11.92 & 5.05 \\
\hline Vulnerability to Harm or Illness & 14.49 & 5.93 \\
\hline Enmeshment/Underdeveloped Self & 14.20 & 7.12 \\
\hline Failure & 12.31 & 6.35 \\
\hline Entitlement/Grandiosity & 15.25 & 5.75 \\
\hline Insufficient Self-control/Self-discipline & 14.22 & 5.26 \\
\hline Subjugation & 14.48 & 6.90 \\
\hline Self-sacrifice & 18.99 & 6.70 \\
\hline Emotional Inhibition & 15.00 & 5.90 \\
\hline Unrelenting Standards/Hyper Critical- & 16.16 & 5.15 \\
\hline ness & & \\
\hline The Total Score of the EMS & 211.70 & 58.37 \\
\hline Problem-focused Coping Style & 45.69 & 9.08 \\
\hline Emotion-focused Coping Style & 43.18 & 9.29 \\
\hline Avoidance Coping Style & 48.13 & 8.65 \\
\hline Fear of Cancer Recurrence & 92.17 & 20.29 \\
\hline Abbreviaton: EMS, early & &
\end{tabular}

${ }^{a}$ Abbreviation: EMS, early maladaptive schemas

maladaptive schemas and coping strategies with FCR in female patients with BC. The findings showed that early maladaptive schemes of emotional inhibition, unrelenting standards, entitlement, enmeshment/ underdeveloped self, and insufficient self-control/ self-discipline have significant correlations with the FCR. Unrelenting standards fall under the over vigilance and inhibition domain. People whose schemas are in this domain often tend to suppress their emotions and impulses. As a result of this parenting style, they learn to be attentive to the negative events of life which are why these people often experience pessimism, worry, and fear. This schema reflects
Table 3: Correlations Between Early Maladaptive Schemas, Coping Styles, and Fear of Cancer Recurrence (FCR)

\begin{tabular}{|lcc}
\hline & FCR (r) & P Value \\
\hline Abandonment/Instability & 0.11 & 0.238 \\
Emotional Deprivation & -0.03 & 0.710 \\
\hline Mistrust/Abuse & -0.02 & 0.854 \\
\hline Social Isolation/Alienation & 0.04 & 0.701 \\
\hline Defectiveness/Shame & 0.12 & 0.210 \\
\hline Dependence/Incompetence & -0.01 & 0.964 \\
\hline Vulnerability to Harm or Illness & 0.18 & 0.054 \\
\hline Enmeshment/Underdeveloped Self & 0.27 & $<0.001$ \\
\hline Failure & 0.04 & 0.628 \\
\hline Entitlement/Grandiosity & 0.28 & $<0.001$ \\
\hline Insufficient Self-control/Self-discipline & 0.24 & $<0.001$ \\
\hline Subjugation & 0.14 & 0.124 \\
\hline Self-sacrifice & 0.12 & 0.193 \\
\hline Emotional Inhibition & 0.35 & $<0.001$ \\
\hline Unrelenting Standards/Hypercriticalness & 0.28 & $<0.001$ \\
\hline The total Score of the EMS & 0.22 & $<0.001$ \\
\hline Problem-focused Coping Style & 0.07 & 0.452 \\
\hline emotion-focused Coping Style & 0.50 & $<0.001$ \\
\hline Avoidance Coping Style & 0.20 & $<0.001$ \\
\hline & & \\
\hline
\end{tabular}

a Abbreviation: EMS, early maladaptive schemas

the beliefs of perfectionists [14]. Furthermore, Judit et al., concluded that adaptation to $\mathrm{BC}$ is directly related to anxious and insecure attachment and maladaptive schemas [27]. Accordingly, when faced with unrelenting cancer diagnosis standards, the person is over-vigilant to the physical symptoms and effectiveness of treatment and falls into the trap of a cycle of obsessive thoughts and rumination. To cope with his/her fears and obsessive thoughts, the person turns to undergo frequent unnecessary examinations and screenings which in the long run reinforces the anxiety and FCR [28, 29]. Besides, the limitations that cancer treatment impose could

Table 4: The Results of Regression Analysis for Predicting the Fear of Cancer Recurrence (FCR) Based on Early Maladaptive Schemas and Coping Strategies ${ }^{\mathrm{a}}$

\begin{tabular}{|c|c|c|c|c|c|c|c|}
\hline & \multirow{2}{*}{ B } & \multirow{2}{*}{ SE } & \multirow{2}{*}{$\beta$} & \multirow{2}{*}{$\mathbf{t}$} & \multirow{2}{*}{ P Value } & \multicolumn{2}{|c|}{ Multicollinearity indexes } \\
\hline & & & & & & Tolerance & Inflation factor \\
\hline Constant & 47.36 & 7.420 & - & 6.38 & $<0.001$ & - & - \\
\hline Emotion-focused Coping Style & 1.10 & 0.195 & 0.504 & 5.65 & $<0.001$ & 0.666 & 1.50 \\
\hline Enmeshment/Underdeveloped Self & 1.19 & 0.346 & 0.303 & 3.43 & $<0.001$ & 0.680 & 1.47 \\
\hline Emotional Inhibition & 0.88 & 0.331 & 0.255 & 2.65 & $<0.001$ & 0.572 & 1.75 \\
\hline Insufficient Self-control/Self-discipline & 0.94 & 0.318 & 0.251 & 2.95 & $<0.001$ & 0.732 & 1.37 \\
\hline Unrelenting standards/Hypercriticalness & 0.70 & 0.337 & 0.178 & 2.08 & $<0.001$ & 0.722 & 1.38 \\
\hline
\end{tabular}

${ }^{\mathrm{a}} \mathrm{DW}=1.70, \mathrm{R} 2=0.41, \mathrm{P} \leq 0.001, \mathrm{~F}=15.37$ 
be an obstacle to achieving the unrelenting standards set. Thus they try to avoid the risk of cancer recurrence and the resulting helplessness may lead to maintaining anxiety, initiating disturbing thoughts, and reinforcing the FCR. People with the emotional inhibition schema have difficulty expressing their emotions and vulnerabilities. The important point about this schema is that it is often a cultural schema. Certain cultures value self-control and believe that showing emotions and talking about them is not admirable. Consistent with the findings of this study, a study examined the experience of FCR in Taiwanese women with BC and showed that the women were reluctant to express their feelings because of community expectations and family commitments. However, they suffered and felt isolated as they were more likely to lose mutual support [30].

Individuals with the entitlement/grandiosity schema believe that they are superior to others and consider special rights and privileges for themselves. The relationship between this schema and the FCR can be explained because the diagnosis of cancer and the limitations it can cause in the individuals, impair their sense of superiority and challenge the sense of invulnerability so that they develop anxiety $[10,31]$. Following a study by Rashidi et al., on the relationship between early maladaptive schemas and illness anxiety disorder, it can be argued that anxiety disorder is a kind of defense against excessive attention of cancer patients. This pattern of behavior predisposes a person to anxiety. Accordingly, the FCR can be considered to be originated from the excessive self-attention of these people [32]. People with ineffective self-control/self-discipline schema often have difficulty with self-control, i.e., the ability to control their emotions and impulses, and self-discipline, i.e., the ability to tolerate failure. In mild forms of this schema, the patient strongly avoids discomfort, does not tolerate pain, and avoids taking responsibility [14]. Accordingly, it can be argued that cancer diagnosis and the FCR may be a failure for these people as they seem not to have learned to deal with it effectively. Thus, people with this schema are more likely to avoid the pain and frustration resulting from cancer recurrence. This avoidance may temporarily reduce their anxiety but in the long run, it reinforces the FCR and increases rumination and anxiety.
The enmeshment/undeveloped self-schema falls under the impaired autonomy and performance domain. People whose schemas are in this domain usually are grown up in families that lower the child's self-esteem and thus lose the ability to function independently. These people cannot form an independent identity and set specific goals for themselves. As a result, people with the enmeshment schema often experience feelings of emptiness, confusion, and aimlessness [14]. Understanding self-efficacy is crucial in assessing threats such as cancer and the strategies one chooses to deal with them. Dunn et al., also showed that understanding self-efficacy through the choice of a coping strategy is associated with FCR. People with the enmeshment schema are unable to function independently and in the face of cancer diagnosis and recurrence, underestimate their ability to deal with it, and may use ineffective coping strategies such as distraction, rumination, and avoidance that lead to FCR [33]. Besides, these people are also more likely to have difficulty in cancer diagnosis situations that require re-evaluating and re-creating meaning which in turn increases their anxiety [34]. The findings of the present study confirmed a positive and significant relationship between addiction-oriented and avoidance coping strategies and the FCR. Similarly, previous studies have shown that people with a higher FCR tend to use inefficient avoidance and avoidance-oriented strategies [28, 35]. One study found that women who used cognitive coping strategies such as seeking emotional support, prayer, or meditation, were constantly thinking about their cancer and how to deal with it, and this may make them excessively more vigilant to recurrence and thus increase FCR [36].

When the aspects of the cancer diagnosis and control situation are uncontrollable, the problem-solving approach is not possible or severely limited, and attempts to control the situation could be ineffective. The attempt to control these negative feelings can be activated by trying to deal with annoying thoughts, reduce emotional arousal, avoid the current threat, and prevent further cancer threats, including avoiding cancer-related symptoms, rumination, distraction, and excessive lifestyle changes, and excessive reassurance seeking. Temporary release from difficult internal experiences reinforces the use of these coping strategies and maintains 
anxiety. This cycle of using inefficient and avoidant emotion-focused coping strategies causes the person to not process their thoughts effectively and not to be able to re-evaluate them positively. Furthermore, suppressing cancer-related thoughts may increase the experience of disturbing thoughts because trying to suppress these thoughts inadvertently strengthens attention and monitoring of their presence, changes the way information is processed and leads to increased alertness and difficulty in releasing from these thoughts [10, 37]. Moreover, if avoiding cancer reminders is the main way to deal with it, one may continue to engage in predefined activities without paying attention to the limitations of cancer. However, if this is not possible, the person may abandon all activities that gave a sense of purpose to his/her life. This makes the person feel more trapped in cancer subsequences, and this in turn is associated with symptoms of psychological trauma in cancer patients [10]. A survey of BC patients in this study indicated that emotion-oriented strategies and the schema such as enmeshment/undeveloped self, emotional inhibition, ineffective self-control/ self-discipline, and unrelenting standards were able to explain about $41 \%$ of the variances in FCR. There is a consensus that previous schemas and beliefs interact with the inherent nature of cancer to cause anxiety and stress. When the fear of death, uncertainty, and lack of control are intense, people tend to use coping strategies to manage their anxiety. Patients usually use different coping strategies that can be adaptive or maladaptive when facing different aspects of the cancer experience. There is also a two-way relationship between pre-existing factors and coping styles; meaning that adaptive coping styles create corrective experiences; while maladaptive coping styles reinforce dysfunctional beliefs [10, 38]. Curran et al., showed that although coping strategies are associated with FCR, they cannot predict it because coping strategies are activated in response to the FCR and may increase or decrease it over time [9].

Generally, a person's past experiences, beliefs, and attitudes influence his or her assessments of why cancer occurs and how it affects his/her future and coping strategies. Thus, early maladaptive schemas which are deep cognitive constructs that distort inconsistent information when activated, can affect a person's sense of cancer experience and make him or her vulnerable to psychological distresses such as FCR. Furthermore, the adoption of ineffective coping strategies reinforces maladaptive schemas; making it difficult to re-evaluate and construct meaning and increasing the anxiety level [10]. FCR is considered a complex and difficult human experience and has special meanings for each person and requires individualized therapists [39, 40]. As revealed in this study, it is suggested that patients' early maladaptive schemas should be taken into account in the intervention process. Besides, despite advances in treatment procedures, no one can guarantee a cancer-free future, so teaching patients effective coping strategies to effectively deal with the risk of recurrence should be on therapists' agenda. This study was performed on volunteer BC patients in only five of the hospitals in Tehran. Thus, it is difficult to generalize the results of the study to other populations and settings. The research sample only included patients with $\mathrm{BC}$ receiving radiotherapy. Thus, the results have limited generalizability to other cancer groups. This study was conducted to provide a better understanding of the factors involved in the FCR. Therefore, future studies could explore the content of patients' beliefs, past experiences, and attachment style in interaction with schemas and the role they play in creating the FCR.

\section{ACKNOWLEDGMENTS}

The authors sincerely appreciate the participants and the staff and managers of the hospitals of Tehran who helped us in carrying out this research project.

\section{CONFLICT OF INTEREST}

The authors declare that they have no conflicts of interest.

\section{ETHICS APPROVAL}

This research was registered at Khatam University (Code: IR.KHATAM.REC.1399.3).

\section{REFERENCES}

1. Akbari ME, Sayad S, Sayad S, Khayamzadeh M, Shojaee L, Shormeji Z, et al. Breast Cancer Status in Iran: Statistical Analysis of 3010 Cases between 1998 and 2014. Int J Breast Cancer. 2017;2017:2481021. DOI: 10.1155/2017/2481021 PMID: 29201466.

2. Roshandel G, Ghanbari-Motlagh A, Partovipour E, Salavati F, Hasanpour-Heidari S, Mohammadi G, et al. Cancer incidence in Iran in 2014: Results of the Iranian National Popula- 
tion-based Cancer Registry. Cancer Epidemiol. 2019;61:508. DOI: 10.1016/j.canep.2019.05.009 PMID: 31132560.

3. Simard S, Savard J, Ivers H. Fear of cancer recurrence: specific profiles and nature of intrusive thoughts. J Cancer Surviv. 2010;4(4):361-71. DOI: 10.1007/s11764-010-0136-8 PMID: 20617394.

4. Vickberg SM. The Concerns About Recurrence Scale (CARS): a systematic measure of women's fears about the possibility of breast cancer recurrence. Ann Behav Med. 2003;25(1):16-24. DOI: 10.1207/S15324796ABM2501 03 PMID: 12581932 .

5. Almeida SN, Elliott R, Silva ER, Sales CMD. Fear of cancer recurrence: A qualitative systematic review and meta-synthesis of patients' experiences. Clin Psychol Rev. 2019;68:13-24. DOI: 10.1016/j.cpr.2018.12.001 PMID: 30617013.

6. Yang Y, Cameron J, Bedi C, Humphris G. Fear of cancer recurrence trajectory during radiation treatment and follow-up into survivorship of patients with breast cancer. BMC Cancer. 2018;18(1):1002. DOI: 10.1186/s12885018-4908-2 PMID: 30342495.

7. Fardell JE, Thewes B, Turner J, Gilchrist J, Sharpe L, Smith A, et al. Fear of cancer recurrence: a theoretical review and novel cognitive processing formulation. J Cancer Surviv. 2016;10(4):663-73. DOI: 10.1007/s11764-0150512-5 PMID: 26782171.

8. Curran L, Sharpe L, MacCann C, Butow P. Testing a model of fear of cancer recurrence or progression: the central role of intrusions, death anxiety and threat appraisal. J Behav Med. 2020;43(2):225-36. DOI: 10.1007/s10865-01900129-x PMID: 31907743.

9. Curran L, Sharpe L, Butow P. Anxiety in the context of cancer: A systematic review and development of an integrated model. Clin Psychol Rev. 2017;56:40-54. DOI: 10.1016/j.cpr.2017.06.003 PMID: 28686905.

10. Gotze H, Taubenheim S, Dietz A, Lordick F, Mehnert-Theuerkauf A. Fear of cancer recurrence across the survivorship trajectory: Results from a survey of adult longterm cancer survivors. Psychooncology. 2019;28(10):203341. DOI: $10.1002 /$ pon.5188 PMID: 31364222.

11. Christ G, Messner C, Behar L. Handbook of oncology social work: Psychosocial care for people with cancer. 1st ed New York, NY, USA: Oxford University Press; 2015.

12. Young JE, Klosko JS. Reinventing Your Life: The Breakthough Program to End Negative Behavior...and FeelGreat Again: Penguin Publishing Group; 1994. 384 p.

13. Young JE, Klosko JS, Weishaar ME. Schema therapy: A practitioner's guide. New York, NY, USA: Guilford Press; 2006. 436 p.

14. Young JE. Cognitive therapy for personality disorders: A schema-focused approach. 3rd ed. Sarasota, FL, USA: Professional Resource Press. Professional Resource Exchange; 1999. $83 \mathrm{p}$.

15. Lazarus RS, Folkman S. Stress, appraisal, and coping. New York, NY, USA: Springer Publishing Company; 1984. 456 p.

16. Khodabakhshi Koolaee A, Falsafinejad MR, Akbari ME. The Effect of Stress Management Model in Quali- ty of Life in Breast Cancer Women. Iran J Cancer Prev. 2015;8(4):e3435. DOI: 10.17795/ijcp-3435 PMID: 26478793.

17. World Health Organization. Cancer Geneva, Switzerland: WHO; 2021 [updated 2021 Sep 21; cited 2021 Dec 26]. Available from: https://www.who.int/news-room/factsheets/detail/cancer.

18. Sengun Inan F, Ustun B. Fear of Recurrence in Turkish Breast Cancer Survivors: A Qualitative Study. J Transcult Nurs. 2019;30(2):146-53. DOI: 10.1177/1043659618771142 PMID: 29708040 .

19. Shakeri J, Kamangar M, Ebrahimi E, Aznab M, Shakeri H, Arman F. Association of Coping Styles with Quality of Life in Cancer Patients. Indian J Palliat Care. 2015;21(3):298304. DOI: 10.4103/0973-1075.164890 PMID: 26600698.

20. Bateni FS, Rahmatian M, Kaviani A, Simard S, Soleimani M, Nejatisafa A. The Persian version of the fear of cancer recurrence inventory (FCRI): Translation and evaluation of its psychometric properties. Arch Breast Cancer. 2019;6(4):174-80. DOI: 10.32768/abc.201964174-180.

21. Schmidt NB, Joiner TE, Young JE, Telch MJ. The schema questionnaire: Investigation of psychometric properties and the hierarchical structure of a measure of maladaptive schemas. Cognit Ther Res. 1995;19(3):295-321. DOI: 10.1007/BF02230402.

22. Oei TPS, Baranoff J. Young Schema Questionnaire: Review of psychometric and measurement issues. Aust J Psychol. 2007;59(2):78-86. DOI: 10.1080/00049530601148397.

23. Ahi G, Mohammadifar M, Besharat M. Reliability and validity of the short form of the Young Schema Questionnaire. J Psychol Educ Sci. 2007;37(3):5-20.

24. Endler NS, Parker JD. Multidimensional assessment of coping: a critical evaluation. J Pers Soc Psychol. 1990;58(5):844-54. DOI: 10.1037//0022-3514.58.5.844 PMID: 2348372.

25. Shokri O, Taghilou S, Geravand F, Paeizi M, Moulaei M, abd Elahpour M, et al. Factor structure and psychometric properties of the farsi version of the coping inventory for stressful situations (CISS). Adv Cogn Sci. 2008;10(3):22-33.

26. Judit D, Eszter H, Julia H, Magdolna D, Laszlo N. Attachment, early maladaptive schemas and subjective experiences of illness in women with breast cancer/Kotodes, korai maladaptiv semak es szubjektiv betegsegelmeny emlorakkal kuzdo noknel. Magyar Pszichológiai Szemle. 2017;72(1):127-46

27. Thewes B, Butow P, Bell ML, Beith J, Stuart-Harris R, Grossi M, et al. Fear of cancer recurrence in young women with a history of early-stage breast cancer: a cross-sectional study of prevalence and association with health behaviours. Support Care Cancer. 2012;20(11):2651-9. DOI: 10.1007/s00520-011-1371-x PMID: 22328003.

28. Tauber NM, O’Toole MS, Dinkel A, Galica J, Humphris G, Lebel S, et al. Effect of Psychological Intervention on Fear of Cancer Recurrence: A Systematic Review and Meta-Analysis. J Clin Oncol. 2019;37(31):2899-915. DOI: 10.1200/JCO.19.00572 PMID: 31532725.

29. Lai WS, Shu BC, Hou WL. A qualitative exploration of the 
fear of recurrence among Taiwanese breast cancer survivors. Eur J Cancer Care (Engl). 2019;28(5):e13113. DOI: 10.1111/ecc.13113 PMID: 31180170.

30. Yalom ID. Existential psychotherapy. France: Hachette UK; 2020.

31. Rashidi M, Khodabakhshi-koolaee A, Vahedian Ardakani H. Comparison of Spiritual Experiences and Hope between Breast Cancer Survivors and Healthy Counterparts. J Clin Basic Res. 2019;3(2):21-6. DOI: 10.29252/jcbr.3.2.21.

32. Dunn LB, Langford DJ, Paul SM, Berman MB, Shumay DM, Kober K, et al. Trajectories of fear of recurrence in women with breast cancer. Support Care Cancer. 2015;23(7):2033-43. DOI: 10.1007/s00520-014-2513-8 PMID: 25524004.

33. Park CL. Making sense of the meaning literature: an integrative review of meaning making and its effects on adjustment to stressful life events. Psychol Bull. 2010;136(2):257301. DOI: 10.1037/a0018301 PMID: 20192563.

34. De Vries J, Den Oudsten BL, Jacobs PM, Roukema JA. How breast cancer survivors cope with fear of recurrence: a focus group study. Support Care Cancer. 2014;22(3):70512. DOI: 10.1007/s00520-013-2025-y PMID: 24193220.

35. Freeman-Gibb LA. The relationship of illness representations and coping to fear of recurrence in breast cancer pa- tients. [Michigan, USA]: University of Michigan; 2012. p.

36. Wells A, Matthews G. Modelling cognition in emotional disorder: the S-REF model. Behav Res Ther. 1996;34(1112):881-8. DOI: 10.1016/s0005-7967(96)00050-2 PMID: 8990539.

37. Cordova MJ, Andrykowski MA. Responses to cancer diagnosis and treatment: posttraumatic stress and posttraumatic growth. Semin Clin Neuropsychiatry. 2003;8(4):286-96. PMID: 14613054.

38. Simard S, Thewes B, Humphris G, Dixon M, Hayden C, Mireskandari S, et al. Fear of cancer recurrence in adult cancer survivors: a systematic review of quantitative studies. J Cancer Surviv. 2013;7(3):300-22. DOI: 10.1007/ s11764-013-0272-Z PMID: 23475398.

39. Simard S, Savard J. Fear of Cancer Recurrence Inventory: development and initial validation of a multidimensional measure of fear of cancer recurrence. Support Care Cancer. 2009;17(3):241-51. ․ DOI: 10.1007/s00520-008-0444-y PMID: 18414902 .

40. Thewes B, Lebel S, Seguin Leclair C, Butow P. A qualitative exploration of fear of cancer recurrence (FCR) amongst Australian and Canadian breast cancer survivors. Support Care Cancer. 2016;24(5):2269-76. DOI: 10.1007/ s00520-015-3025-x PMID: 26581900. 